\title{
THE MECHANISM OF THE OSMOTIC ADJUSTMENT OF BODY CELLS AS DETERMINED IN VIVO BY THE VOLUME OF DISTRIBUTION OF A LARGE WATER LOAD ${ }^{1}$
}

\author{
BY ALEXANDER LEAF,2 JACQUES Y. CHATILLON, OLIVER WRONG, AND \\ ELBERT P. TUTTLE, JR. ${ }^{3}$ \\ (From the Departments of Medicine, Massachusetts General Hospital and Harvard Medical \\ School, Boston, Mass.)
}

(Submitted for publication April 5, 1954 ; accepted May 14, 1954)

Since permeability of cell membranes to water has been clearly demonstrated, there are several theoretically possible responses of cells to dilution of the extracellular fluid. Osmotic equilibrium might result from net movement of water into cells in response to extracellular dilution. On the other hand, net movement of water into cells might be averted by: 1) active transport of water out of cells preventing a change in intracellular osmotic activity ; 2) reduction of intracellular osmotic activity by means of either osmotic inactivation of intracellular solutes or their extrusion from the cells.

These possibilities were tested by determining the volume of distribution of a large water load which depends on movement of water through the body. The data are compared with the total body water content measured by the dilution of a tracer amount of deuterium oxide which is independent of net movement of water. In the dog the volume of distribution of a large water load was found to approximate closely the total body water content.

\section{METHODS AND PROCEDURE}

\section{A. Protocol}

Fifteen initial experiments were performed in nine unanesthetized dogs. Two and one-half to five units of Pitressin Tannate in Oil 4 were given two to sixteen hours before the experiment to reduce the urinary loss of water. After the bladder was emptied by catheterization, the animal was weighed and a control blood sample ob-

1 This study was supported in part by grants from the Milton Fund of Harvard University, the American Heart Association, and the Greater Boston Chapter of the Massachusetts Heart Association.

2 Howard R. Hughes Fellow in Medicine.

8 Postdoctorate Fellow in Medicine, National Heart Institute, U. S. Public Health Service.

4 Kindly provided by Dr. A. C. Bratton, Jr., Parke, Davis and Company, Detroit, Michigan. tained. A water load of $100 \mathrm{ml}$. per kilogram of body weight was then administered intravenously at a rate of approximately $20 \mathrm{ml}$. per minute. The water load was given as a $2 \frac{1}{2}$ per cent solution of dextrose, or dextrose and fructose. Blood samples were obtained following the infusion at intervals of three to sixty minutes for five or six hours in three experiments. In the other experiments blood samples were taken 4 to 6 hours after the infusion was completed. Some of the dogs received 0.3 $\mathrm{mgm}$. of atropine and $50 \mathrm{mgm}$. of Dramamine to prevent vomiting and salivation.

A second series of ten experiments was performed on dogs either nephrectomized or with ureters ligated. The operation was done under local procaine infiltration (10 to $20 \mathrm{ml}$. of 1 per cent solution) in two animals and in the remainder under general anesthesia induced and maintained throughout the experiment by the intravenous administration of 25 to $30 \mathrm{mgm}$. of sodium pentobarbital per kilogram of body weight. Immediately following operation a blood sample for the natural abundance of deuterium was drawn, and 1 to 2 grams of deuterium oxide per kilogram of body weight were given intravenously. Blood was drawn one and one-half and two hours later for determination of deuterium and as control samples before dilution. Dramamine and atropine were administered as above. One hundred and thirty-two $\mathrm{ml}$. per kilogram of body weight of a 2.5 per cent solution of fructose and/or glucose were administered intravenously at a rate of $30 \mathrm{ml}$. per minute. This quantity of water was chosen to increase the degree of dilution and thus to minimize the effects of the errors of measurement on the calculated results. The two final blood samples were obtained between $2 \frac{1}{2}$ and $31 / 2$ hours after the infusion was completed. The ureteral ligatures were removed from four dogs, all of which recovered uneventfully. In one of these the experiment was later repeated.

\section{B. Analytical methods}

Plasma sodium and potassium concentrations were measured by flame photometry (1). Total solute concentration of plasma was determined by the freezing point depression measured with a thermistor. ${ }^{5}$ Deuterium concentrations were measured by mass spectrometry (2).

5 The apparatus was developed and constructed for us by Fiske Associates, Inc., 44 Bromfield Street, Boston, Mass. 
Urea was determined by the microdiffusion technique of Conway (3); glucose by the method of Nelson modified by Somogyi (4) ; fructose by the method of Rolf, Surtshin, and White (5); chloride by the method of Wilson and Ball (6). Plasma water was measured gravimetrically after drying at $95^{\circ}$ to $105^{\circ} \mathrm{C}$. to constant weight. Data were analyzed by conventional statistical methods (7).

\section{Calculations and analytical error}

In the calculations of the last ten experiments the values for sodium, total solutes and deuterium are the averages of repeated determinations made on two separate plasma samples obtained at short intervals, as described above. The errors of the methods were estimated by the analysis of variance of these repeated determinations. The coefficient of variation for a single determination of plasma sodium concentration was 0.95 per cent; of total solute concentration, 0.75 per cent; and of deuterium, 1.55 per cent. As all analyses were done at least in quadruplicate the estimate of the analytical error for the averages used in the calculations was reduced to one-half or less of the above figures for single determinations.

The volume of distribution of the water load was calculated by the following general equation:

$$
\mathrm{V}=\frac{\mathrm{C}_{2} \mathrm{~W}}{\mathrm{C}_{1}-\mathrm{C}_{2}}
$$

$\mathrm{V}=$ volume $^{6}$ of distribution of the water load.

$C_{1}$ and $C_{2}=$ initial and final plasma concentrations of sodium or total solutes.

$\mathrm{W}=$ volume of water administered.

Total body water content was calculated as follows:

$$
\mathrm{V}_{\mathrm{D}_{2} \mathrm{O}}=\frac{18}{20} \mathrm{~W}_{\mathrm{D}_{2} \mathrm{O}}\left(\frac{100-\mathrm{F}}{\mathrm{F}}\right)
$$

$\mathrm{V}_{\mathrm{D}_{2} \mathrm{O}}=$ deuterium space (total body water content).

$W_{D_{2} O}=$ weight of deuterium oxide administered.

$F=$ atoms per cent excess of deuterium in plasma at equilibrium.

The volumes, as calculated, had a minimum standard deviation attributable to propagation of the errors of measurements alone (8) estimated to be: 1.4 to 2.4 per cent of body weight for the sodium calculations, 1.6 to 3.0 per cent of body weight for total solute calculations, and approximately 0.5 per cent of body weight for the deuterium space.

\section{RESULTS}

The results obtained in the initial fifteen experiments performed in nine dogs are briefly summarized in Table I. These results were calculated according to Equation 1 with no attempt to correct the data for the small renal losses of water and solute that occurred during the experiments.

- No distinction has been made between liters and kilograms of water.
TABLE I

The mean volume of distribution of an intravenous water load in 15 experiments

Mean $\mathrm{V}_{\mathrm{Na}}=65.6 \%$ of Body Weight

Mean $\mathrm{V}_{\text {sol }}=63.6 \%$ of Body Weight

Mean Difference $\quad=1.9 \%$ of Body Weight

Standard Deviation $=2.3 \%$ of Body Weight (of Mean Difference)

$t_{14}$

$=0.86$

p

$=0.4$

Analysis of variance reveals no significant difference between the mean volumes of distribution of the water load calculated from changes in concentration of plasma sodium $\left(\mathrm{V}_{\mathrm{Na}_{\mathrm{a}}}\right)$ and total solute $\left(V_{\text {sol }}\right)$, but the standard deviation for the differences between $V_{\mathrm{Na}}$ and $\mathrm{V}_{\mathrm{Sol}}$ in individual experiments was large ( 8.9 per cent body weight). The results approximate the expected value for total body water in the dog.

Because of the considerable discrepancy between $V_{\mathrm{Na}}$ and $\mathrm{V}_{\mathrm{Sol}}$ in individual experiments, ten further studies were done. To reduce errors resulting from renal losses of water and solutes, either the dogs were nephrectomized or their ureters were ligated immediately prior to the experiment.

Figure 1 shows the effects of a water load on the total solute, sodium, glucose and urea concentrations of plasma in a nephrectomized dog. Equilibrium of distribution of the water load occurred within two hours. The plasma urea concentration slowly increased during the study as might be expected in a nephrectomized animal. The plasma glucose concentration was still elevated above the control levels at the end of the experiment.

The data for the last ten experiments are presented in Table II. The quantity of water administered was chosen to cause a large dilution of the body fluids with minimal toxic effects. The serum sodium concentrations after the water load are in a range not uncommonly seen clinically. In eight experiments there occurred a slight rise in plasma urea concentration in spite of the dilution. This accumulation of urea is attributable to the suppression of renal function. In all experiments the blood glucose level was still elevated at the time the last blood samples were drawn. This 


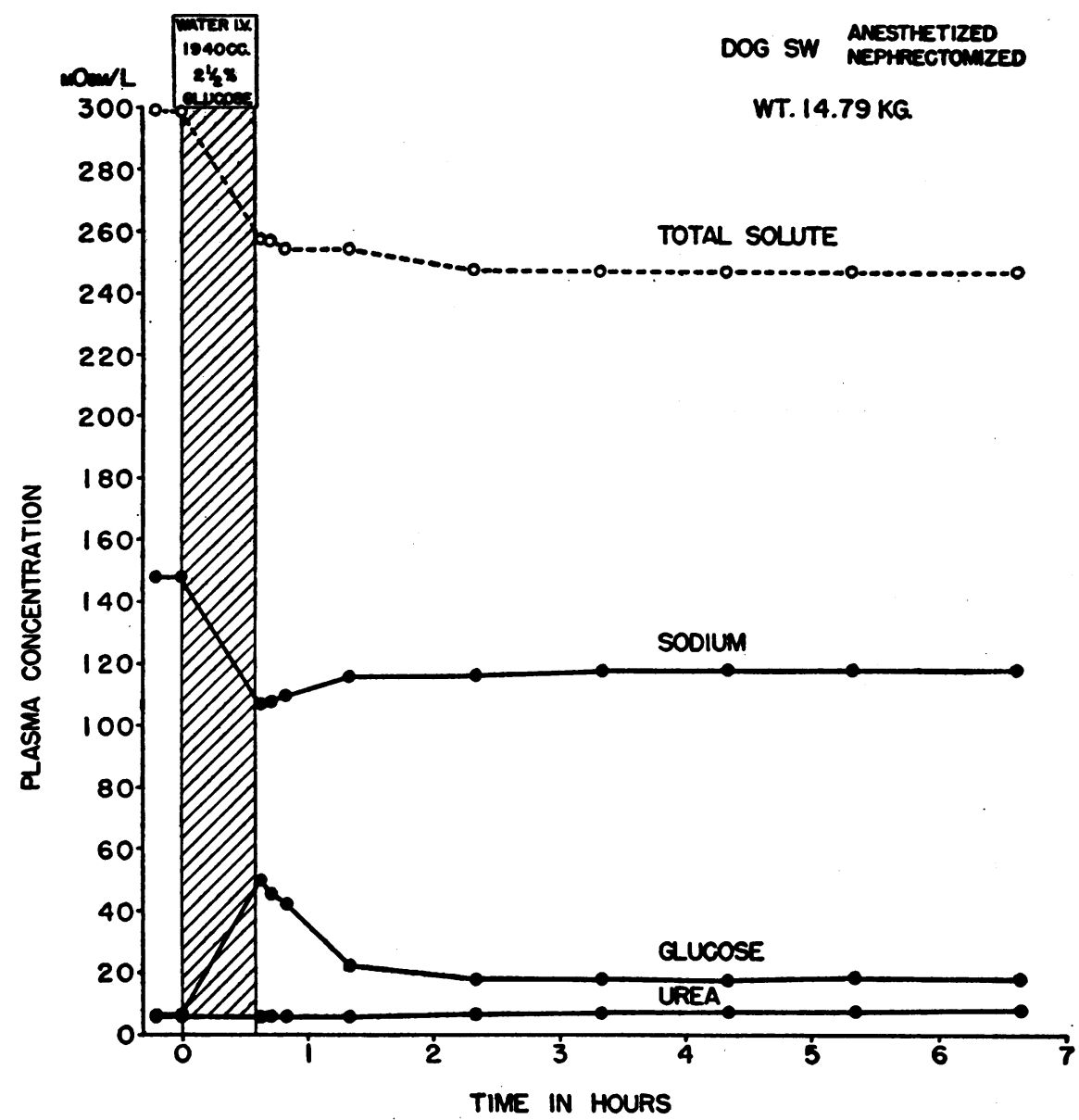

Fig. 1. Changes in Total Solute, Sodium, Glucose and Urea Concentrations in Plasma following the Intravenous Administration of a Large Water Load to A NepHrectomized Dog

It is evident that the plasma concentrations of sodium and total solutes had achieved constant values by $2 \frac{1}{2}$ hours following termination of the infusion. In this experiment the plasma glucose remained elevated after the infusion (see text).

was true even when fructose alone was used in the infusing solution. The concentrations of fructose in the plasma, however, never rose more than 1.3 $\mathrm{mM}$ per L. The persistent hyperglycemia probably reflects reduced glucose tolerance resulting from the meat diet used prior to the experiment." The serum potassium concentrations decreased slightly in all but two experiments. In the two experiments in which serum potassium concentration rose the changes were too small to reflect significant extrusion of intracellular potassium in response to extracellular dilution.

7 Three days of glucose administration prior to the experiment in subsequent studies abolished the prolonged hyperglycemia noted in the present results.
Table III shows the volume of distribution of the large water load calculated from changes in plasma sodium $\left(\mathrm{V}_{\mathrm{Na}}\right)$ and total solute $\left(\mathrm{V}_{\mathrm{Sol}}\right)$ concentrations, respectively. The total body water content before dilution, determined as the volume of distribution of deuterium oxide $\left(\mathrm{VD}_{2} \mathrm{O}\right)$, is also shown. To facilitate comparison, all results are expressed as per cent of body weight. The plasma urea concentrations have been subtracted from the total solute concentrations used to calculate $V_{\text {sol }}$ in Tables III and IV to correct for the accumulation of urea during the experiments. This correction is justified because urea is known to be freely distributed over total body water.

The results in Table III are subdivided into 


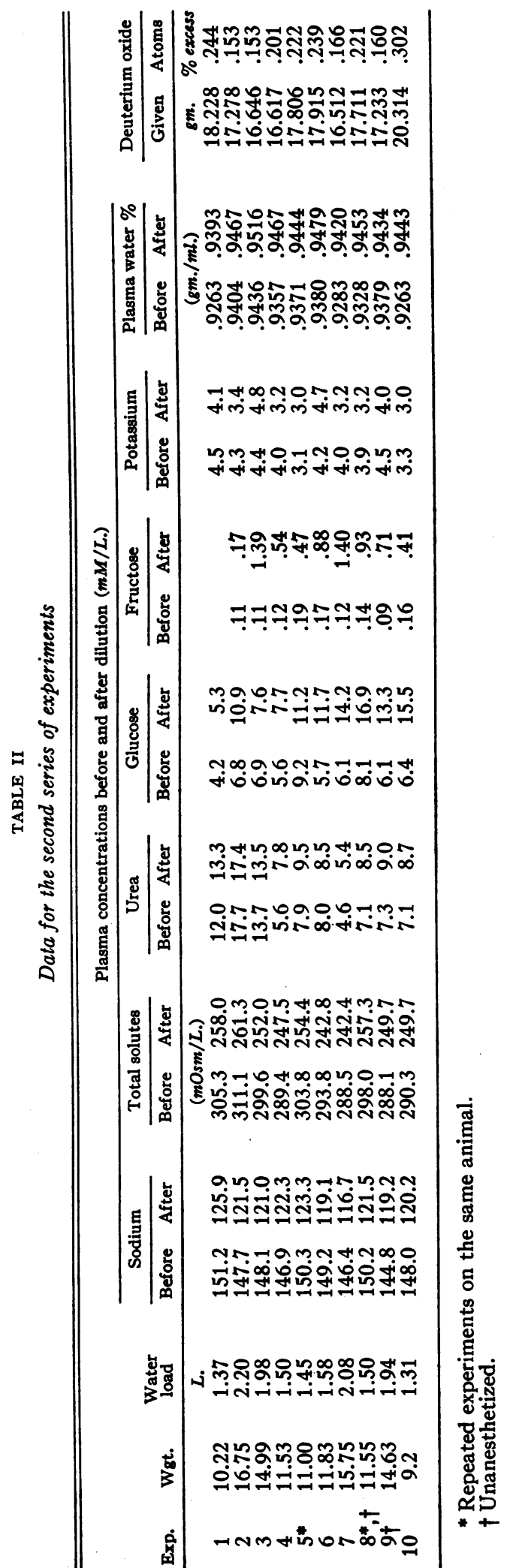

two groups according to the magnitude of the rise in plasma glucose concentration $(\Delta G)$ that occurred between the initial and the final blood specimens. Although in all experiments, $\mathrm{V}_{\text {Sol }}$ is larger than $V_{\mathrm{Na}}$, the five experiments in Group I show an excellent agreement among $\mathrm{V}_{\mathrm{Na}}, \mathrm{V}_{\mathrm{sol}}$, and $\mathrm{V}_{\mathrm{D}_{2}} \mathrm{O}$. The discrepancies in each experiment within this group are of the magnitude expected from the analytical and sampling errors. The value of $\Delta G$ for this group of results is small. In Group II of Table III, the discrepancies between $\mathrm{V}_{\mathrm{Na}}$ and $\mathrm{V}_{\text {sol }}$ are considerably larger, as are the values of $\Delta G$. Figure 2A shows the relationship between $\Delta G$ and the difference between $\mathrm{V}_{\text {sol }}$ and $\mathrm{V}_{\mathrm{Na}}$ for all experiments. The correlation coefficient, 0.88 , is significant.

The accumulation of glucose or any other solute during the course of an experiment will result in a final concentration of total solutes which is too high and will minimize the expected dilution of plasma total solutes. This would cause falsely high values for $\mathrm{V}_{\text {sol. }}$. If glucose accumulates in an osmotically active form in the extracellular fluid, it not only will result in an over-estimation of $V_{\text {sol, }}$, but also would be expected to reduce $\mathrm{V}_{\mathrm{Na}}$. The osmotically active glucose in the extracellular fluid would cause the movement of some intracellular water to the extracellular compartment. This would dilute the plasma sodium in excess of the dilution produced by the water load and $\mathrm{V}_{\mathrm{Na}}$ would be underestimated. An attempt has, therefore, been made to correct the results of Table III for the measured changes in plasma glucose.

In Table IV, $\mathrm{V}_{\mathrm{Na}}$ and $\mathrm{V}_{\mathrm{Sol}}$ have been corrected on the assumption that the rise in glucose concentration occurred over a volume of 30 per cent of body weight. This volume of distribution of diffusible glucose in the dog has recently been reported by Searle, Strisower, and Chaikoff (9). Details of this calculation are presented in the Appendix; it should be noted that the volume of distribution assumed for glucose does not enter into the correction applied to the calculation of $\mathrm{V}_{\mathrm{Na}}$. The values of $\mathrm{VD}_{2} \mathrm{O}$ are again presented to facilitate comparison. The correction for plasma water content and the Donnan effect, though insignificant, was also applied to $\mathrm{V}_{\mathrm{Na}}$ (see Appendix).

The correction for glucose abolishes the significant correlation of $\mathrm{V}_{\mathrm{Sol}}-\mathrm{V}_{\mathrm{Na}}$ and $\Delta \mathrm{G}$ (Figure 
TABLE III

Uncorrected volume of distribution of administered water (Expressed as per cent of body weight)

\begin{tabular}{ccccc}
\hline \hline Experiment & $\Delta G \dagger$ & $V_{N_{2}}$ & $V_{\text {Bol }}$ & $V_{\text {Dso }}$ \\
\hline Group $I$ & & & & \\
1 & 1.09 & 66.7 & 67.5 & 65.6 \\
2 & 4.09 & 60.8 & 64.6 & 60.6 \\
3 & 0.75 & 58.9 & 66.4 & 65.2 \\
4 & 2.13 & 64.6 & 70.8 & 64.5 \\
$5^{*}$ & 1.95 & 60.3 & 63.3 & 65.5 \\
& & & & \\
Group II & & & & \\
6 & 6.04 & 52.8 & 60.8 & 57.0 \\
7 & 8.14 & 52.0 & 66.7 & 56.8 \\
$8^{*}$ & 8.78 & 54.8 & 76.8 & 62.4 \\
9 & 7.17 & 61.5 & 79.7 & 66.2 \\
10 & 9.05 & 61.7 & 81.5 & 65.7 \\
& & & & \\
\hline
\end{tabular}

* Repeated observations on the same animal.

$\dagger \Delta G$ is the difference in concentration of plasma glucose before and after dilution.

$V_{N_{2}}$ and $V_{\text {Bol }}$ are the volumes of distribution of the water load calculated from changes in plasma sodium and total solute concentrations, respectively.

$\mathrm{V}_{\mathrm{D}_{2} \mathrm{O}}$ is the total body water content determined from dilution of deuterium oxide.

2B). It is apparent from Table IV that the calculation of the volume of distribution of a large water load is essentially the same whether estimated from the dilution of serum sodium or total
TABLE IV

Volume of distribution of administered water corrected for glucose, Donnan effect, and plasma water content (Expressed as per cent of body weight)

\begin{tabular}{cccc}
\hline \hline Experiment & VXa & VBol & VDsO \\
\hline 1 & 66.2 & 66.0 & 65.6 \\
2 & 64.1 & 60.5 & 60.6 \\
3 & 59.6 & 64.8 & 65.2 \\
4 & 61.9 & 67.9 & 64.5 \\
5 & 67.0 & 60.6 & 65.5 \\
6 & 57.4 & 55.9 & 57.0 \\
7 & 54.0 & 59.4 & 56.8 \\
8 & 56.5 & 67.0 & 62.4 \\
9 & 63.1 & 71.0 & 66.2 \\
10 & 62.6 & 71.1 & 65.7 \\
Mean & 61.2 & 64.4 & 63.0 \\
\hline
\end{tabular}

Standard deviation of differences between means

$$
\begin{array}{lll}
V_{\text {Sol }}-V_{N_{2}}=1.80 ; & t=1.76 ; & p>.05 \\
V_{D_{2} O}-V_{N_{2}}=0.96 ; & t=1.76 ; & p>.05 \\
V_{\text {Bol }}-V_{D_{2}}=1.03 ; & t=1.43 ; & p>.05
\end{array}
$$

solutes. Furthermore these values closely approximate the total body water content $\left(\mathrm{VD}_{2} \mathrm{O}\right)$.

\section{DISCUSSION}

Studies with deuterium oxide have clearly demonstrated that cell membranes are permeable to

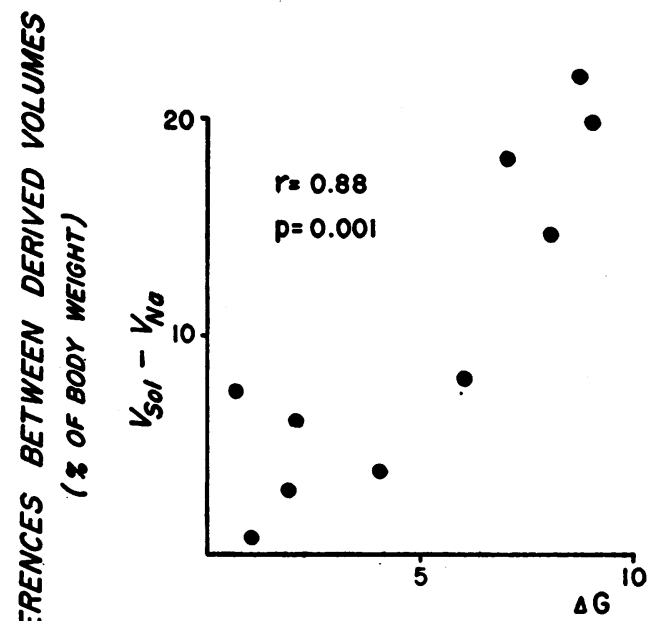

(A)

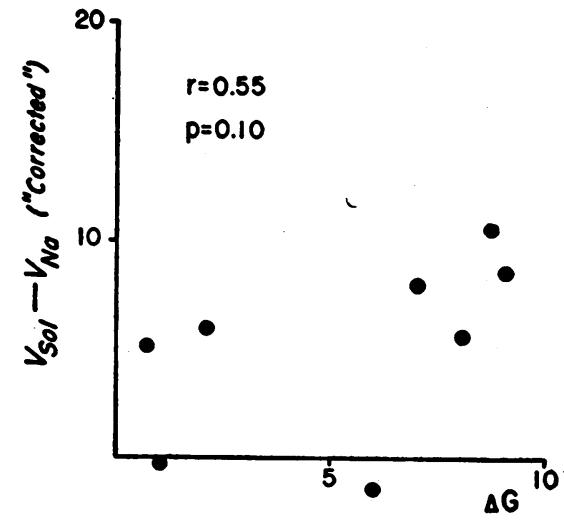

(B)

CHANGES IN PLASMA GLUCOSE CONCENTRATION $\left(\mathrm{mO}_{\mathrm{s}} \mathrm{mL}\right)$

Fig. 2. The Correlation between Changes in Plasma Glucose Concentrations, $\Delta$ G, aNd the Dipferences between V Minus V Na $_{\text {(B) }}$

The correlation is significant in A, but not significant in $\mathrm{B}$. 
water. The distribution of a small quantity of deuterium oxide throughout total body water is dependent upon the movement of individual molecules and does not require net passage of water across cell membranes. Hence, the knowledge that deuterium oxide equilibrates with total body water yields no information about the osmotic adjustments of the cells when a large quantity of water is introduced into the body.

The results of the present study strongly suggest that the volume of distribution of a large water load is equal to the total body water content. Thus in vivo the osmotic adjustment of the great majority of body cells involves net movement of water into cells so that the water load appears to be evenly distributed throughout total body water.

This interpretation of the present findings seems contradictory to the conclusions of Robinson and McCance $(10,11)$, who observed that respiring rat kidney slices maintained essentially constant weight in media of varying concentrations, whereas slices whose respiration had been inhibited swelled in these media. They concluded that the cells are normally hypertonic to their environment and that inward diffusion of water is counteracted by an equal and active transport of water out of the cells. Such a mechanism would prevent net movement of water into cells and the apparent volume of distribution of a water load should then approximate only the volume of the extracellular fluid. The present findings exclude the widespread occurrence of such active water transport by cells though it is possible within the errors of measurement of this study that a single tissue or organ might behave in the manner claimed by Robinson. However, Mudge has shown (12) in experiments with kidney slices that shifts of electrolytes as well as of water may occur across renal cell membranes making Robinson's data subject to other interpretations. The findings of Opie (13) that several tissues swell in vitro in media hypertonic to normal extracellular fluid are not pertinent to the present study as they give no information of the response of these tissues to dilution of their environment in vivo. Furthermore this worker fails to explain why such swelling of tissues does not occur in vivo.

The present study yields results representing the average response of the body cells to dilution. It is, therefore, not possible to deny that some cells take up more than their quota of the water load whereas other cells take up less. It seems unlikely, however, that certain cells are diluted more than the average in an amount just sufficient to yield a volume of distribution for various water loads apparently equal to total body water.

If enough intracellular solute were extruded from the cells, $V_{\text {sol }}$ might equal total body water. $\mathrm{V}_{\mathrm{Na}}$, however, would be significantly lower unless the extruded solute were sodium. An attempt was made to determine whether sodium was extruded from bones or cells. The ratio of sodium to chloride in bone and most cells is much higher than in the extracellular fluid. If sodium were extruded into the extracellular fluid one might expect a greater dilution of chloride than of sodium. In two instances the dilution of sodium and of chloride were identical. In the other experiments the chloride dilution was highly variable and the discrepancies between sodium and chloride dilution correlated closely with the volume of gastric secretions which accumulated during the experiments. It seems improbable that sodium would move out of bone and cells in all experiments in an amount just sufficient to increase $\mathrm{V}_{\mathrm{Na}}$ to the value of $\mathrm{VD}_{\mathrm{D}_{2} \mathrm{O}}$ in spite of differences in the water loads that were administered. For these reasons, it seems unlikely that extrusion of sodium from cells or bone contributes significantly to the osmotic adjustment to a water load.

The osmotic inactivation of intracellular solutes might be an alternative adjustment requiring no net movement of water into cells. This possibility must be excluded since it would result in a volume of distribution of the water load significantly less than total body water.

The present results give no indication whether the osmotic pressure is the same or different in the intracellular and extracellular fluids. In either case, however, the even distribution of the water load over total body water indicates that the concentration ratio is the same before and after dilution. Osmotic equality throughout the total body water would be the simplest explanation consistent with the present results. This view has been accepted and clearly stated by Peters (14) and is in agreement with recent cryoscopic measurements 
of various tissues by Conway and McCormack (15).

This study is complementary to earlier work of Hetherington (16) and Eggleton (17) and recent studies of Wolf and McDowell (18). These workers added hypertonic saline to the extracellular fluid and measured the apparent volume of body water that diluted the administered salt. The average results of Hetherington, Wolf, and McDowell and those of Eggleton, as recalculated by Conway and McCormack (15) yielded fair approximations of total body water content.

\section{SUMMARY AND CONCLUSIONS}

In twenty-five experiments, eighteen dogs were given large water loads under conditions which minimized or eliminated renal losses. The volume of distribution of the water load was calculated from the changes in plasma concentrations of sodium and total solutes. In ten experiments total body water content was simultaneously determined by the dilution of deuterium oxide.

The volume of distribution of the water load as determined from the dilution of plasma solute (64.4 per cent of body weight) and sodium (61.2 per cent) concentrations was equal to total body water content ( 63.0 per cent) within the limits of experimental error. The findings indicate that in vivo the great majority of the body cells adjust to acute dilution of the extracellular fluid by a net movement of water into the cells so that the administered water load is distributed evenly over total body water content.

\section{ACKNOWLEDGMENTS}

The authors wish to thank Miss Denise Girod and Miss Mineko Sasahara for their assistance in this study. A Supply Grant from the National Institutes of Health in support of a Public Health Service Postdoctorate Research Fellowship to one of us (E. P. T.) was used in this study.

\section{APPENDIX}

$\mathrm{W}=$ Water load in liters.

$\mathrm{V}_{1}=$ Volume of distribution of the water load.

$\mathrm{V}_{2}=\mathrm{V}_{1}+\mathrm{W}$.

$\alpha=$ Coefficient of dilution, equals $\frac{V_{1}}{V_{1}+W}$, after equilibrium.

$m_{1}, m_{2}=$ Fraction of $V_{1}$ and $V_{2}$, respectively, containing osmotically active glucose. $n_{1}, n_{2}=$ Fraction of $V_{1}$ and $V_{2}$, respectively, containing sodium at its concentration $\mathrm{Na}_{1}$ and $\mathrm{Na}_{2}$. Concentrations in plasma of sodium, glucose $\mathrm{Na}_{1}, \mathrm{Na}_{2}$ and total-solutes-minus-urea before and after $\left.G_{1}, G_{2}\right\}=$ dilution. $\mathrm{Na}$ and $\mathrm{G}$ concentrations are ex$S_{1}, S_{2}$ pressed as millimoles per liter; $S$, in milliosmoles per liter.

$\mathrm{K}=$ The factor by which $\mathrm{Na}_{2}$ is corrected for overdilution as a result of accumulation of glucose.

$f=$ The factor by which plasma sodium concentration is corrected for plasma water content and the Donnan effect.

\section{Correction of $V_{\text {sol }}$ for change in glucose}

The total amount of solutes in $\mathrm{m}_{2} \mathrm{~V}_{2}$ is the same as the amount in $\mathrm{m}_{1} \mathrm{~V}_{1}$ plus the added glucose which is not metabolized :

(3) $\mathrm{m}_{2} \mathrm{~V}_{2} \mathrm{~S}_{2}=\mathrm{m}_{1} \mathrm{~V}_{1} \mathrm{~S}_{1}+\left(\mathrm{m}_{2} \mathrm{~V}_{2} \mathrm{G}_{2}-\mathrm{m}_{1} \mathrm{~V}_{1} \mathrm{G}_{1}\right)$

It is assumed that the glucose concentrations, $G_{1}$ and $G_{2}$, are uniform throughout their respective volumes of distribution, $\mathrm{m}_{1}$ and $\mathrm{m}_{\mathbf{2}}$.

The increase in concentration, $\Delta \mathrm{S}$, of total solutes resulting from this unmetabolized glucose is:

$$
\Delta \mathrm{S}=\frac{\mathrm{m}_{2} \mathrm{~V}_{2} \mathrm{G}_{2}-\mathrm{m}_{1} \mathrm{~V}_{1} \mathrm{G}_{1}}{\mathrm{~V}_{2}}
$$

Replacing $m_{2}$ by its value obtained from (3):

$$
\Delta S=m_{1} \alpha\left[\frac{S_{1}-G_{1}}{S_{2}-G_{2}} G_{2}-G_{1}\right]
$$

Thus the general equation (1) permits calculation of $\mathrm{V}_{\mathrm{Bol}}$ corrected for change in glucose:

$$
V_{1}=\frac{W}{\frac{S_{1}}{S_{2}-\Delta S}-1}
$$

II. Correction of $V_{\mathrm{Na}}$ for change in glucose and for plasma water content and the Donnan factor

The increase in osmotically active glucose in the extracellular fluid may be expected to draw water from cells. This will result in overdilution of the plasma sodium which may be corrected by a factor:

$$
\mathrm{K}=\frac{\mathrm{n}_{2} \mathrm{~V}_{2}}{\mathrm{n}_{1} \mathrm{~V}_{2}}
$$

As $\frac{m_{2}}{m_{1}}=\frac{n_{2}}{n_{1}}$, equations (3) and (7) may be combined to yield :

$$
\mathrm{K}=\alpha \frac{\mathrm{S}_{1}-\mathrm{G}_{1}}{\mathrm{~S}_{2}-\mathrm{G}_{2}}
$$

Plasma sodium concentration was corrected for plasma water content and for the Donnan effect assuming onefourth of the extracellular fluid to be intravascular. The Donnan factor, d, of $\mathbf{0 . 9 6}$ was accepted for a plasma protein concentration of 6 per cent and $(1-d)$ was considered to vary directly with plasma protein concentration. Plasma protein concentration was calculated from plasma water content (gm. per ml.) (19):

$$
f=\frac{0.334}{\text { Plasma Water }}+0.671
$$

Thus the general equation (1) permits calculation of 
$\mathrm{V}_{\mathrm{Na}}$ corrected for change in glucose and for plasma water content and the Donnan effect:

$$
\mathrm{V}_{\mathrm{N} 2}=\frac{\mathrm{W}}{\frac{\mathrm{f}_{1} \mathrm{Na_{1 }}}{\mathrm{Kf}_{2} \mathrm{Na}_{2}}-1}
$$

\section{REFERENCES}

1. Berry, J. W., Chappell, D. G., and Barnes, R. B., Improved method of flame photometry. Indust. \& Engin. Chem. (Anal. Ed.), 1946, 18, 19.

2. Solomon, A. K., Edelman, I. S., and Soloway, S. The use of the mass spectrometer to measure deuterium in body fluids. J. Clin. Invest., 1950, 29, 1311.

3. Hawk, P. B., Oser, B. L., and Summerson, W. H., 12th ed., Practical Physiological Chemistry. Philadelphia, The Blakiston Co., 1947, repr. 1951.

4. Somogyi, M., Notes on sugar determination. J. Biol. Chem., 1952, 195, 19.

5. Rolf, D., Surtshin, A., and White, H. L., A modified diphenylamine procedure for fructose or inulin determination. Proc. Soc. Exper. Biol. \& Med., 1949, 72, 351.

6. Wilson, D. W., and Ball, E. G., A study of the estimation of chloride in blood and serum. J. Biol. Chem., 1928, 79, 221

7. Mather, K., Statistical Analysis in Biology, 2nd ed., rev. and enl. New York, Interscience Publishers, Inc., 1947.

8. Worthing, A. G., and Geffiner, J., Treatment of Experimental Data. New York, John Wiley and Sons, Inc., 1943.
9. Searle, G. L., Strisower, E. H., and Chaikoff, I. L., Glucose pool and glucose space in the normal and diabetic dog. Am. J. Physiol., 1954, 176, 190.

10. Robinson, J. R., Osmoregulation in surviving slices from the kidneys of adult rats. Proc. Roy. Soc., Series B, 1950, 137, 378.

11. Robinson, J. R., and McCance, R. A., Water metabolism. Ann. Rev. Physiol., 1952, 14, 115.

12. Mudge, G. H., Electrolyte and water metabolism of rabbit kidney slices: effect of metabolic inhibitors. Am. J. Physiol., 1951, 167, 206.

13. Opie, E. L., The movement of water in tissues removed from the body and its relation to movement of water during life. J. Exper. Med., 1949, 89, 185.

14. Peters, J. P., Water exchange. Physiol. Rev., 1944, 24, 491.

15. Conway, E. J., and McCormack, J. I., The total intracellular concentration of mammalian tissues compared with that of the extracellular fluid. J. Physiol., 1953, 120, 1.

16. Hetherington, M., The state of water in mammalian tissues. J. Physiol., 1931, 73, 184.

17. Eggleton, M. G., The state of body water in the cat. J. Physiol., 1951, 115, 482.

18. Wolf, A. V., and McDowell, M. E., Apparent and osmotic volumes of distribution of sodium, chloride, sulfate and urea. Am. J. Physiol., 1954, 176, 207.

19. Eisenman, A. J., MacKenzie, L. B., and Peters, J. P., Protein and water of serum and cells of human blood, with a note on the measurement of red blood cell volume. J. Biol. Chem., 1936, 116, 33. 